\title{
FLUXO DE SEIVA E CONDUTÂNCIA ESTOMÁTICA DE DUAS ESPÉCIES LENHOSAS SEMPRE-VERDES NO CAMPO SUJO E CERRADÃO
}

\author{
CHEILA CRISTINA NAVES-BARBIERO ${ }^{1}$, AUGUSTO CÉSAR FRANCO ${ }^{2}$, SANDRA \\ JANET BUCCI ${ }^{3}$, GUILHERMO GOLDSTEIN ${ }^{4}$
}

\author{
Departamento de Botânica, Instituto de Ciências Biológicas, Universidade de Brasília, \\ Caixa Postal 04457, 70.919-970 Brasília - DF, Brasil.
}

\begin{abstract}
RESUMO - No presente estudo, comparou-se o curso diário de fluxo de seiva, condutância estomática e potencial hídrico $(\Psi)$ de duas espécies sempre-verdes, Rapanea guianensis e Roupala montana. Os dados foram obtidos no final da estação seca, quando os efeitos do déficit hídrico seriam mais acentuados. As medidas foram realizadas no campo sujo, onde predomina gramíneas com sistemas radiculares superficiais, e no cerradão, em que a maior densidade de elementos lenhosos com sistemas radiculares profundos poderia levar a um esgotamento das reservas de água do subsolo na estação seca. Valores máximos de $\Psi$ não diferiram para as duas espécies nas duas fisionomias estudadas. Os valores mínimos de potencial hídrico foliar de $R$. guianensis foram mais negativos $(\mathrm{P}<0,05)$ para as plantas do cerradão, enquanto os valores para $R$. montana não apresentaram diferenças entre as duas fisionomias. Os resultados indicaram que não existem diferenças significativas $(\mathrm{P}>0,05)$ entre os valores de fluxo máximo e de fluxo total entre o campo sujo e cerradão. Os valores máximos de fluxo de seiva variaram entre 0,13 e $0,221 . \mathrm{h}^{-1}$ para $R$. guianensis e entre 0,15 e $0,541 . \mathrm{h}^{-1}$ para $R$. montana. Entretanto, as duas espécies, tanto no campo sujo quanto no cerradão, apresentaram um rígido controle estomático em relação à alta demanda evaporativa da atmosfera. O fluxo de seiva aumentou bruscamente pela manhã, alcançando rapidamente valores máximos entre 8 e 10 horas, e logo após decresceu severamente, apesar do crescente aumento da radiação solar e da demanda evaporativa da atmosfera.
\end{abstract}

TERMOS ADICIONAIS PARA INDEXAÇÃO: Rapanea guianensis, Roupala montana, transpiração, cerrado, potencial hídrico.

\section{SAP FLOW AND STOMATAL CONDUCTANCE OF TWO EVERGREEN WOODY SPECIES IN AN OPEN SAVANNA AND A SAVANNA WOODLAND}

\footnotetext{
ABSTRACT - The climate in the central Brazilian's savannas ("cerrados") is characterized by welldefined dry (May to September) and wet (October to April) seasons. Like other tropical savannas, a landscape mosaic forms the Brazilian savannas where the predominance and size of woody elements varies the most. The present study compared the daily course of sap flow, stomatal conductance and leaf water potential ( $\Psi$ ) of two evergreen species, Rapanea guianensis and Roupala montana. The measurements were taken at the end of the dry season when the effects of water deficits are more intense.

Recebido em 6/11/1999 e aceito em 10/5/2000

1. Eng ${ }^{\mathrm{a}}$. Agr ${ }^{\mathrm{a}}$., MS - Coordenação de Pesquisa e Pós-graduação, Centro Universitário Luterano de Palmas, Caixa Postal 160 , 77.054-970 - Palmas, TO, Brasil..

2. Professor, PhD - Departamento de Botânica. Instituto de Ciências Biológicas, UnB, Caixa Postal 04457, 70919-970, Brasília DF, Brasil. Autor para correspondência.

3. Bióloga, Estudante de Doutorado - Departamento de Biologia, Universidad de Buenos Aires, Ciudad Universitaria Nunez, Buenos Aires, Argentina.

4. Professor, PhD - Department of Botany, University of Hawaii, 3190 Maile Way, Honolulu, HI 956822, USA.
} 
These measurements were taken in an open savanna area with a predominant grass layer with superficial root system ("campo sujo") and in a woodland savanna ("cerradão"), where the increase in density of deep-rooted trees result in a larger exploitation of soil water resources in the dry season. Maximum values of $\Psi$ did not differ between the two species or the two vegetation types. R. guianensis minimum values of $\Psi$ were significantly lower $(\mathrm{P}<0.05)$ in the woodland savannas ("cerradão"). On the other hand, R. montana minimun $\Psi$ did not differ between sites. Maximum values of sap flow and total daily sap flow did not differ $(\mathrm{P}>0.05)$ between the "campo sujo" and the "cerradão" savannas. Maximum values of sap flow were between 0.13 and $0.221 . \mathrm{h}^{-1}$ for $R$. guianensis and 0.15 and $0.541 .1 . \mathrm{h}^{-1}$ for $R$. montana. In both vegetation types the two species showed a strong stomatal control of transpiration. Sap flow typically increased sharply in the morning, briefly attained a maximum value by about $08.00-10.00 \mathrm{~h}$ then decreased sharply despite steadily increasing solar radiation and atmospheric evaporative demand.

ADDITIONAL INDEX TERMS: Rapanea guianensis, Roupala montana, transpiration, savanna, water.

\section{INTRODUÇÃO}

O cerrado é o segundo bioma em extensão no Brasil, ocupando mais de 2.000.000 de $\mathrm{Km}^{2}$. Como outras savanas tropicais, o cerrado é caracterizado por um mosaico de paisagens em que variam especialmente a predominância e o porte dos elementos lenhosos.

Rawitsher et al., (1943) estimaram que nos solos do cerrado haveria água suficiente para manter a vegetação por pelo menos três anos, mesmo na ausência total de chuvas, contrariando Warming (1892), que considerou a escassez de água como o principal fator limitante para esse tipo de fitofisionomia. Rawitsher (1948) realizou vários experimentos, constatando que os estômatos das plantas lenhosas ficavam abertos durante o dia todo e que o curso diário da transpiração acompanhava o da umidade relativa do ar. Quando as plantas sofriam escassez de água, os estômatos fechavam apenas parcialmente em determinadas horas do dia, para restabelecer sua condição hídrica ideal. A maioria das espécies estudadas não fechou totalmente os estômatos, mesmo em condições de seca mais severas.

Espécies do estrato arbustivo, arbóreo e herbáceo de um cerradão no Estado de São Paulo apresentaram uma diminuição acentuada dos valores de potencial hídrico e condutância estomática durante a época seca (Perez e Moraes, 1991). Na estação chuvosa, com a reposição de água no solo, os valores de potencial hídrico e condutância estomática aumentaram substancialmente. Moraes e Prado (1998) observaram que os valores de fotossíntese, condutância estomática e transpiração de várias espécies em um cerrado sensu strictu sofreram uma severa restrição durante a época seca. Franco (1998), trabalhando com Roupala montana, uma espécie sempre-verde do cerrado, verificou que a espécie reduziu consideravelmente a abertura estomática na época da seca, mas os valores de potencial hídrico foliar medidos ao amanhecer sofreram pouca variação, dimuindo de $0,2 \mathrm{MPa}$ na estação chuvosa para $-0,4 \mathrm{MPa}$ na estação seca.

Todos esses estudos utilizaram métodos que medem a taxa de transpiração de uma folha individual ou de uma região da folha. $\mathrm{O}$ método mais apropriado para medir transpiração no que se refere a indivíduo, podendo ser combinado com medidas de condutância estomática em nível foliar, é a utilização de sensores que medem o fluxo de seiva pelo xilema do caule (Granier et al., 1996; Smith e Allen 1996). Recentemente, Meinzer et al., (1999) utilizaram sensores de fluxo de seiva para estudar a regulação hídrica em quatro espécies arbóreas sempre-verdes, em um cerrado sensu strictu do Distrito Federal. Esses autores constataram que essas espécies exerceram um rígido controle da transpiração, via um controle estomático pronunciado, levando a limitações no fluxo de seiva tanto na estação seca como na estação chuvosa.

A vegetação do cerrado apresenta uma grande variedade de tipos fisionômicos, que diferem quanto à predominancia dos elementos 
lenhosos. Os tipos fisionômicos mais característicos são o campo limpo, campo sujo, cerrado sensu stricto e cerradão. Segundo Coutinho (1978), o campo limpo caracteriza-se pela predominância de plantas herbáceas; o campo sujo, pela presença de árvores e arbustos isolados ao longo da paisagem; o cerrado sensu stricto, pela ocorrência de árvores e arbustos, e o cerradão, pela dominância de espécies lenhosas de dossel alto e fechado. Devido às variações na estrutura da vegetação, as relações hídricas de uma mesma espécie podem mudar entre uma área em que o estrato arbustivo-arbóreo é descontínuo (campo sujo) e uma área em que a vegetação lenhosa apresenta uma maior densidade (cerradão), especialmente na estação seca. No campo sujo, onde predomina estrato herbáceo com sistemas radiculares superficiais, as camadas mais profundas do perfil do solo permaneceriam úmidas e disponíveis para os indivíduos arbóreos esparsos, mesmo durante a estação seca. No cerradão, a vegetação lenhosas sofreria um déficit hídrico acentuado, devido a maior densidade de árvores com sistemas radiculares profundos, ocorrendo uma sobreposição dessas raízes e, conseqüentemente, competição pelo recurso hídrico, devido ao esgotamento das reservas de água do subsolo.

Portanto, o objetivo deste trabalho foi o de comparar o fluxo de seiva, condutância estomática e potencial hídrico de duas espécies lenhosas típicas do cerrado (Rapanea guianensis e Roupala montana) no campo sujo e no cerradão, durante a estação da seca, visando a determinar se as espécies apresentariam diferentes estratégias de regulação hídrica nas duas fisionomias.

\section{MATERIAL E MÉTODOS}

\section{Área de estudo}

O estudo foi realizado na Reserva Ecológica do IBGE (Instituto Brasileiro de Geografia e Estatística), localizada a $35 \mathrm{~km}$ ao sul de Brasília ( $15^{\circ} 56^{\prime} 41^{\prime}$ 'S e $47^{\circ} 53^{\prime} 07^{\prime}$ ' O), com altitude média de $1.100 \mathrm{~m}$. Segundo a classificação de Koeppen, o clima da região é do tipo Aw, clima tropical de savanas, com uma estação seca bem marcada que, nessa região, se estende de maio a setembro.

Os solos são classificados como Latossolos Vermelho-Escuro, bem drenados, de textura muito argilosa e baixa capacidade de troca catiônica. $\mathrm{Na}$ área de estudo, foram selecionadas duas parcelas de estudo de um hectare, vizinhas, mas que se diferenciavam fisionomicamente. Umas das parcelas apresentava a estrutura típica de um cerradão, enquanto a outra caracterizava-se como uma área de campo sujo. Considerando-se como árvores qualquer espécie lenhosa com caule de pelo menos $4 \mathrm{~cm}$ de diâmetro a $30 \mathrm{~cm}$ do solo e com no mínimo $1 \mathrm{~m}$ de altura, a parcela de cerradão apresentou uma densidade de 3.350 árvores por hectare, e a parcela de campo sujo, 950 arvores por hectare. Em cada uma das parcelas, selecionaram-se cinco indivíduos de duas espécies lenhosas típicas do cerrado, Rapanea guianensis (Lam.) Lundell ) (Mircinaceae) e Roupala montana (Aubl ) (Proteaceae). Entre esses cinco indivíduos selecionados por espécie, três foram usados para as medidas de fluxo de seiva e condutância estomática, e os outros dois, para as medidas de potencial hídrico foliar.

Ambas são espécies sempre verdes, comuns nos cerrados do DF, e que podem atingir porte arbóreo.

\section{Curso diário do fluxo de seiva no xilema e condutância estomática}

O fluxo de seiva no xilema foi medido em três indivíduos de cada espécie estudada, durante quatro dias consecutivos em agosto de 1997, utilizando o método de Granier (Granier, 1985 e 1987). O dispositivo para medir o fluxo de seiva constava de duas sondas de $2 \mathrm{~mm}$ de diâmetro e $2 \mathrm{~cm}$ de comprimento, que foram inseridas no xilema das árvores, separadas por uma distância vertical de $15 \mathrm{~cm}$. As sondas continham um termopar de cobre-constantã no centro de uma agulha hipodérmica. Além do termopar, a sonda superior possuía uma resistência elétrica, alimentada por uma bateria de 12 volts, 
provocando um aumento de temperatura no local de inserção da sonda.

Desta maneira, estabelece-se uma diferença de temperatura entre a sonda superior e a inferior, que é função do fluxo de seiva pelos vasos intactos. Não havendo fluxo, a diferença de temperatura entre as sondas é máxima, e se houver fluxo, o calor da sonda é dissipado por convecção e a diferença de temperatura entre as sondas diminui. A densidade de fluxo $\mathrm{u}\left(\mathrm{kg} \mathrm{dm}^{-2} \mathrm{~s}^{-1}\right)$ foi calculada baseando-se em uma relação empírica determinada para várias espécies (Granier, 1985), modificada para $\mathrm{m} \mathrm{s}^{-1}$

$$
\mathrm{u}=119 \cdot 10^{-2} \cdot \mathrm{K}^{1,23} \quad \text { Eq. [1] }
$$

Em que $\mathrm{K}$ foi calculado pela equação:

$$
\mathrm{K}=\left(\Delta \mathrm{T}_{\text {máx }}-\Delta \mathrm{T}\right) / \Delta \mathrm{T} \quad \text { Eq. [2] }
$$

sendo, $\Delta \mathrm{T}_{\text {máx }}$ e $\Delta \mathrm{T}$ as diferenças de temperatura, quando o fluxo é nulo e maior que zero, respectivamente.

O fluxo (F) em $1 / \mathrm{h}$, foi calculado multiplicando-se a densidade de fluxo pela área de xilema ativo $\left(\mathrm{S}_{\mathrm{a}}\right)$, medido na altura da sonda superior.

$$
\mathrm{F}=\mathrm{u} \cdot \mathrm{S}_{\mathrm{a}} \text { Eq. [3] }
$$

Para a medição da área do xilema ativo, elegeram-se 5 indivíduos de cada espécie com diâmetros de tronco variados. $O$ tronco foi perfurado com uma broca de 3/16" e injetou-se um corante diluído em água. Depois de uma hora, cortou-se o tronco aproximadamente a $2 \mathrm{~cm}$ acima do ponto de injeção do corante; considerou-se como xilema ativo a região tingida de azul celeste pelo corante. Em seguida, tomaram-se em duplicata, medidas do diâmetro da circunferência que delimita internamente e externamente a área corada, pela qual se calculou a área do xilema ativo $\left(\mathrm{S}_{\mathrm{a}}\right)$, segundo a seguinte formula:

$$
\mathrm{S}_{\mathrm{a}}=\pi\left[\left(\mathrm{r}_{\mathrm{e}}\right)^{2}-\left(\mathrm{r}_{\mathrm{i}}\right)^{2}\right] \quad \text { Eq. [4] }
$$

Em que, $\left(\mathrm{r}_{\mathrm{e}}\right)$ é o raio externo e $\left(\mathrm{r}_{\mathrm{i}}\right)$ é o raio interno.

Baseando-se nesses dados, foi feita uma regressão linear entre a área do xilema ativo e o diâmetro do caule, medido após a remoção da casca no local de medição. Estimou-se a área xilemática das árvores medidas tomando-se por base dessa regressão, encontrando os seguintes resultados: Rapanea guianensis obteve $\mathrm{y}=5,68 \mathrm{x}$ 9,87 e um $\mathrm{r}^{2}=0,99$ no campo sujo, e no cerradão de $\mathrm{y}=5,76 \mathrm{x}-10,10$, também com um $\mathrm{r}^{2}=0,99$, Roupala montana apresentou um $\mathrm{r}^{2}=0,97$ e uma equação de $\mathrm{y}=4,83 \mathrm{x}-7,75$. Desta forma, calculou-se a transpiração diária, dividindo-se o fluxo total pela área foliar total de cada indivíduo. A área foliar total de cada indivíduo foi estimada contando-se todas as folhas de cada árvore, e depois retirando-se uma amostra de 10 folhas de cada indivíduo. A área de cada folha foi calculada utilizando-se a metodologia descrita em Caldas et al. (1992). O valor médio da área foliar obtido com base nessas 10 folhas foi multiplicado pelo número de folhas de cada árvore estudada, para obter a área foliar total.

As sondas foram colocadas nos troncos de três árvores de cada espécie, aproximadamente a $20 \mathrm{~cm}$ da superfície do solo, para evitar o aquecimento por condução de calor do solo. As sondas foram envolvidas com espuma e plástico grosso. $\mathrm{O}$ plástico foi vedado com silicone para evitar a infiltração de água da chuva e ataques de insetos. O conjunto foi envolvido com uma manta de amianto, para diminuir o efeito da temperatura externa e a incidência direta do sol.

As sondas foram conectadas a um sistema automático de aquisição e armazenamento de dados ("Datalogger" CR 10; Campbell Scientific Inc, USA), alimentado por uma bateria de 12 volts, possibilitando a obtenção de medidas em três árvores simultaneamente. O "datalogger" foi programado para ler as diferenças de temperatura a cada 15 segundos e armazenar o valor médio obtido em intervalos de 10 minutos. Os dados foram armazenados em um módulo de estado sólido (Storage Module SM196; Campbell Scientific Inc, USA). 
As medidas de condutância estomática (Gs) foram realizadas com um porômetro LI-1600 (LI-COR, USA) nos mesmos indivíduos em que foram instalados os sensores de fluxo de seiva. Gs foi medida em quatro folhas não sombreadas por indivíduo, durante o período luminoso em intervalos de duas horas. As quatro folhas estavam localizadas aproximadamente à mesma altura na copa.

\section{Potencial hídrico foliar.}

O potencial hídrico foliar $(\psi)$ foi medido com uma bomba de pressão (modelo 3005 -1422; Soil Moisture Equipment Corp, USA). As medidas de potencial hídrico foram realizadas durante o período das 6 às $18 \mathrm{~h}$, em intervalos de duas horas, em indivíduos diferentes dos que estavam conectados com as sondas, para evitar a perda da área de transpiração foliar. As folhas foram cortadas na inserção do pecíolo com o ramo, colocadas rapidamente em bolsas plásticas com feixe hermético e mantidas no escuro dentro de um isopor com gelo, para evitar a perda de água por transpiração. Para minimizar a diferença de horários de coleta entre as folhas, foram todas coletadas no mesmo horário, armazenadas no isopor e, em seguida, feitas as medidas de potencial hídrico. A cada medida, foi determinado o potencial hídrico de três indivíduos por espécie, utilizando-se uma folha por indivíduo.

\section{Variáveis microclimáticas}

Entre as duas parcelas estudadas, montou-se uma estação microclimática a $1,5 \mathrm{~m}$ de altura do solo, conectada a um sistema automático de aquisição e armazenamento de dados (Datalogger 21x; Campbell Scientific Inc, USA), que era alimentado por uma bateria de 12 volts, conectada a um painel solar. O "datalogger" foi programado para medir a densidade de fluxo de fótons na faixa de 400 a $700 \mathrm{~nm}$ (DFF), a temperatura e umidade do ar a cada 15 segundos e armazenar o valor médio obtido em intervalos de 10 minutos. A temperatura $\left(\mathrm{T}_{\mathrm{ar}}\right) \mathrm{e}$ a umidade relativa do ar (UR) foram medidas com um sensor Vaisala (HMP 35, Campbell Scientific Inc, USA) e a DFF com um sensor quanta 190-S (Licor, USA).

Calculou-se o déficit de pressão de vapor atmosférico (DPV) pela seguinte fórmula (Jones, 1992):

$$
\mathrm{DPV}=0,611375 e^{t} *\left(1-\frac{\mathrm{UR}}{100}\right) \quad \text { Eq. [5] }
$$

Em que o t é calculado pela equação:

$$
\mathrm{t}=\frac{17,502 *\left(\mathrm{~T}_{\mathrm{ar}}\right)}{\left(240,97+\mathrm{T}_{\mathrm{ar}}\right)} \quad \text { Eq. [6] }
$$

\section{Análise estatística}

Todos os dados apresentavam uma distribuicão normal pelo teste KolmogorovSmirnof. Portanto, as médias foram comparadas pelo teste $\mathrm{T}$, considerando-se como significantes as que diferiram entre si um nível de probabilidade $\mathrm{P}<0,05$ (Sokal e Rohlf 1969). Essas análises foram feitas pelo programa estatístico SPSS para Windows, versão 6.1.2 (1995).

\section{RESULTADOS}

\section{Características gerais das plantas}

Os indivíduos de $R$. guianensis e $R$. montana não se diferenciaram com relação à altura, diâmetro externo , área do xilema ativo, área foliar total e número de folhas entre o campo sujo e o cerradão (Tabela 1). Por outro lado, os indivíduos de $R$. montana apresentaram valores significativamente maiores de diâmetro externo $(\mathrm{P}=0,009)$, área do xilema ativo $(\mathrm{P}=$ $0,014)$ e área foliar total $(\mathrm{P}=0,025)$ do que $R$. guianensis no campo sujo. As duas espécies não diferiram nessas características no cerradão. 
TABELA 1 - Altura, diâmetro externo, área do xilema ativo, área foliar total e número de folhas de três indivíduos de Rapanea guianensis e Roupala montana no campo sujo e no cerradão.

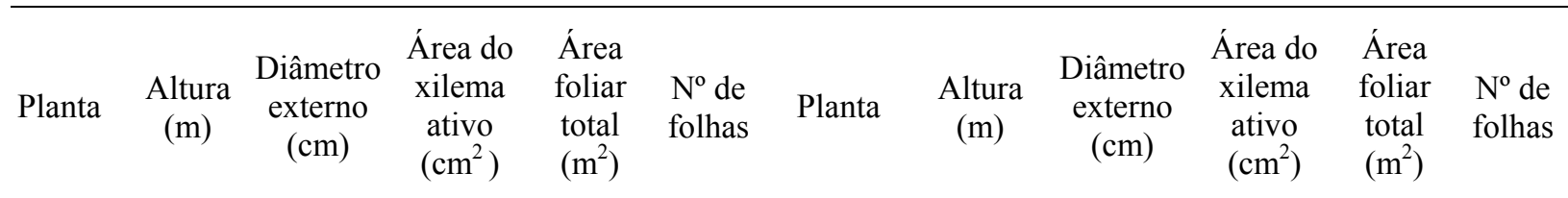

\begin{tabular}{|c|c|c|c|c|c|c|c|c|c|c|c|}
\hline & \multicolumn{5}{|c|}{ Campo sujo } & \multicolumn{6}{|c|}{ Cerradão } \\
\hline \multicolumn{12}{|c|}{ Rapanea guianensis } \\
\hline 1 & 2,37 & 4,40 & 15,20 & 0,68 & 367 & 1 & 2,10 & 3,50 & 10,04 & 1,68 & 593 \\
\hline 2 & 2,40 & 3,65 & 10,90 & 0,70 & 297 & 2 & 2,66 & 3,70 & 11,92 & 0,97 & 358 \\
\hline 3 & 2,30 & 4,25 & 14,34 & 1,49 & 593 & 3 & 2,50 & 3,85 & 12,05 & 0,82 & 323 \\
\hline Média & 2,35 & 4,10 & 13,48 & 0,95 & 419 & Média & 2,42 & 3,68 & 11,33 & 1,15 & 425 \\
\hline
\end{tabular}

Roupala montana

\begin{tabular}{cccccccccccc}
1 & 2,77 & 5,75 & 20,02 & 3,44 & 730 & 1 & 1,10 & 4,00 & 11,57 & 4,05 & 741 \\
2 & 2,30 & 7,30 & 27,50 & 2,93 & 434 & 2 & 3,40 & 6,45 & 23,40 & 1,78 & 327 \\
3 & 2,64 & 6,50 & 24,89 & 5,63 & 1014 & 3 & 2,40 & 4,10 & 12,05 & 1,40 & 256 \\
Média & 2,40 & 6,51 & 24,10 & 4,00 & 726 & Média & 2,30 & 4,85 & 15,67 & 2,41 & 441 \\
\hline
\end{tabular}

Pelas figuras 1 e 2 verificaram-se os padrões diários típicos das variáveis microclimátológicas (déficit de pressão de vapor, densidade de fluxo de fótons fotossinteticamente ativos), fluxo de seiva e condutância estomática para as duas espécies nas duas fisionomias. Os valores máximos de DFF ocorreram por volta do meio-dia, enquanto os valores máximos de DPV ocorreram por volta das $14 \mathrm{~h}$. Os valores máximos de DFF ficaram entre 1555 a $1584 \mu \mathrm{molm}^{-2} \mathrm{~s}^{-1}$, enquanto os valores máximos de DPV estiveram na faixa de 4,0 kPa.
O padrão diário de fluxo de seiva foi semelhante nos indivíduos de $R$. guianensis nas duas fitofisionomias (Figura 1). No campo sujo, a curva de fluxo apresentou dois picos distintos. Um maior, por volta das 9h, quando os valores atingiram $3,8.10^{-5} \mathrm{~m} \mathrm{~s}^{-1}$. O outro pico, que ocorreu as $16 \mathrm{~h}$, alcançou valores máximos de somente $2,01.10^{-5} \mathrm{~m} \mathrm{~s}^{-1}$. No cerradão, Fs apresentou valor máximo 'as $11 \mathrm{~h}$. Após atingir o valor máximo, houve uma queda acentuada do fluxo, com uma pequena recuperação por volta das $15 \mathrm{~h}$. 


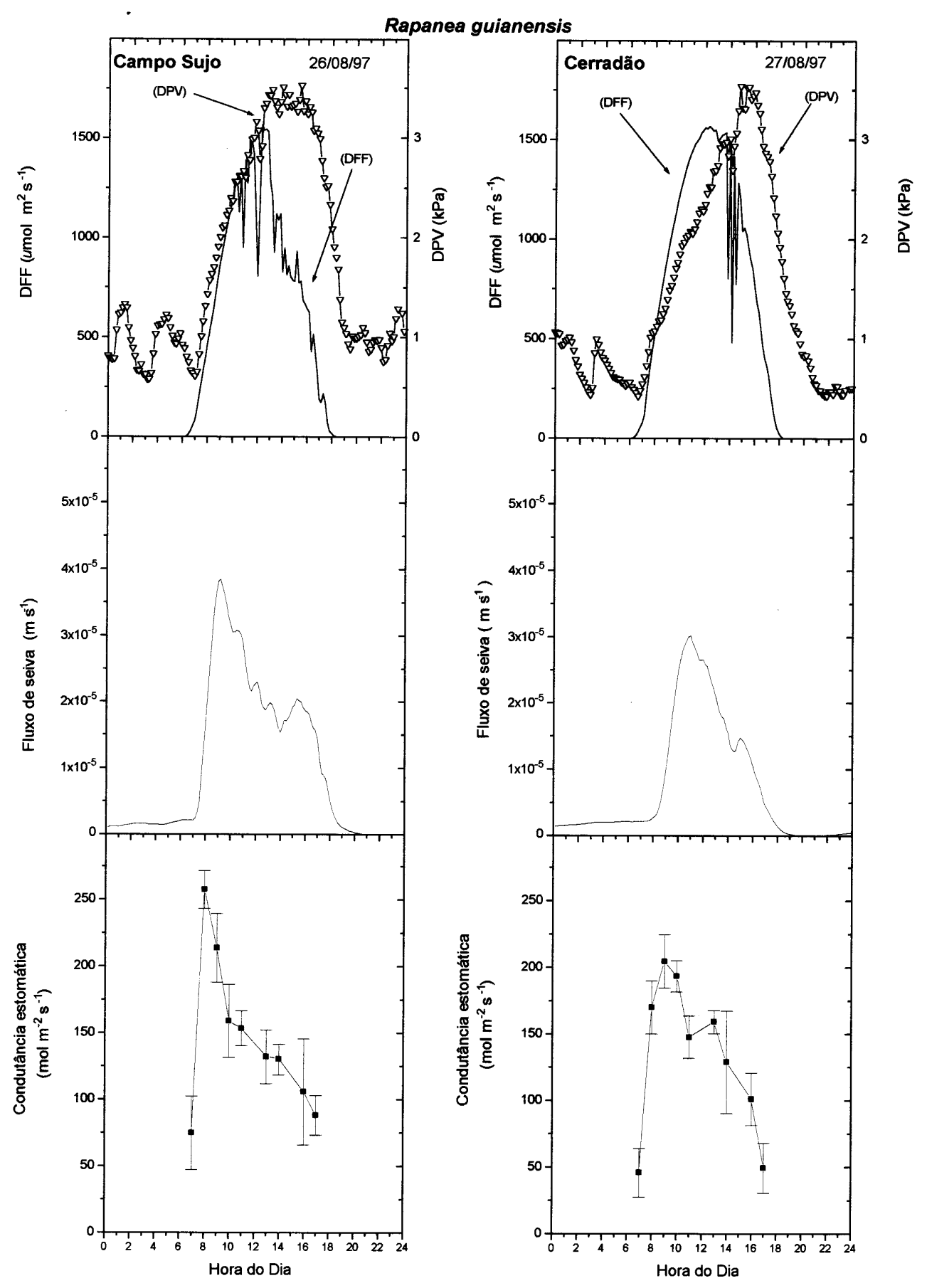

FIGURA 1 - Curso diário de DPV (déficit de pressão de vapor) e DFF (densidade de fluxo de fotóns, fluxo de seiva e condutância estomática da espécie Rapanea guianensis no campo sujo no dia 26/08/97 e no cerradão no dia 27/08/97 


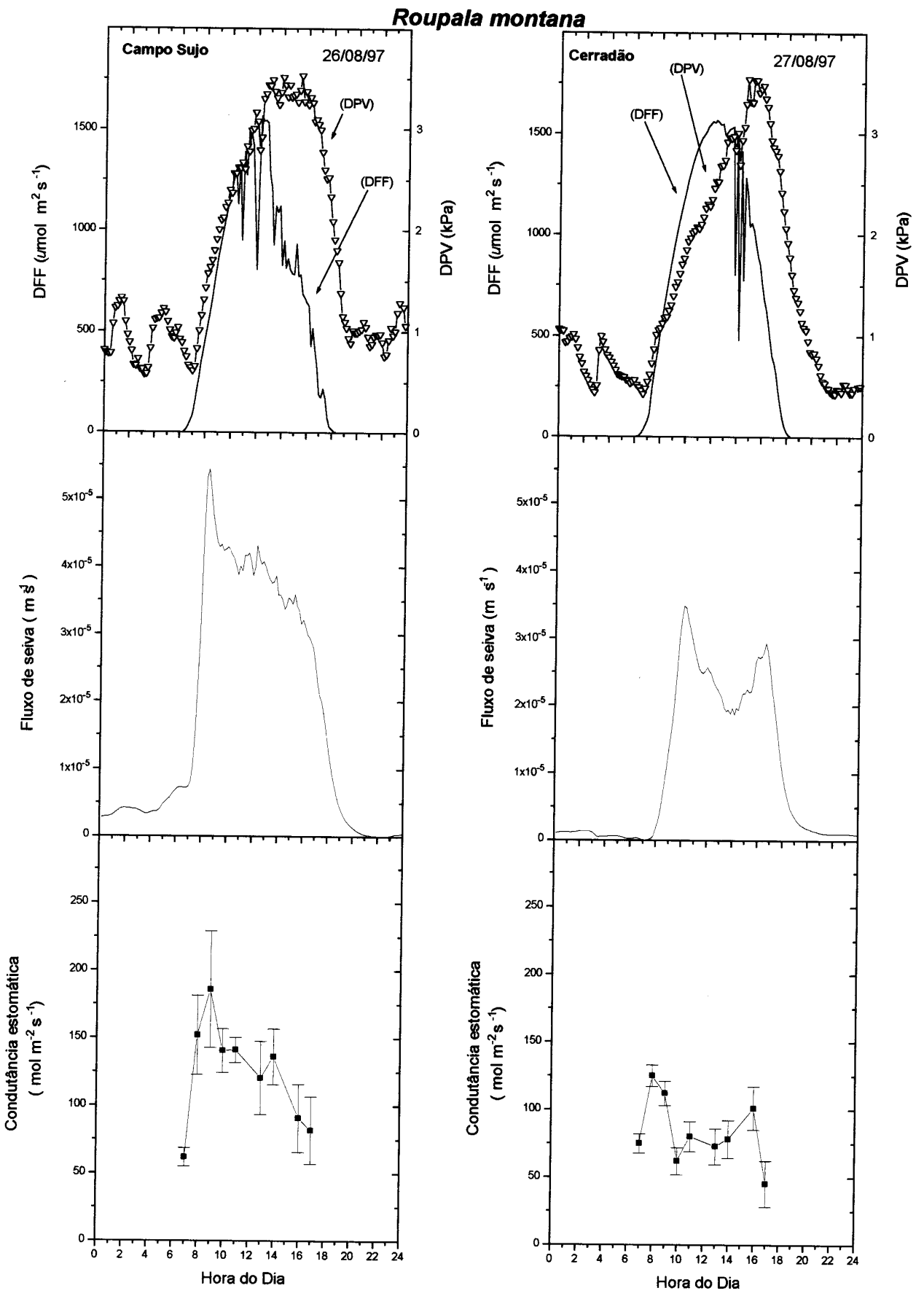

FIGURA 2 - Curso diário de DPV (déficit de pressão de vapor) e DFF (densidade de fluxo de fotóns, fluxo de seiva e condutância estomática da espécie Roupala montana no campo sujo no dia 26/08/97 e no cerradão no dia 27/08/97.

R. Bras. Fisiol. Veg., 12(2):119-134, 2000. 
O Fs atingiu valores próximos a zero por volta das $18 \mathrm{~h}$. A Gs seguiu o mesmo padrão no campo sujo e no cerradão, aumentando seus valores acentuadamente no início da manhã, até atingir os valores máximos entre 8 e $9 \mathrm{~h}$. Após o pico, houve uma queda acentuada de Gs até por volta das $10 \mathrm{~h}$, quando Gs passou a diminuir mais vagarosamente durante $\mathrm{o}$ resto do período luminoso.

Roupala montana, no campo sujo, apresentou um pico bem marcado nos valores de fluxo de seiva por volta das $8 \mathrm{~h}$; após esse pico, Fs caiu lentamente até 'as $16 \mathrm{~h}$, quando sofreu uma diminuição acentuada (Figura 2). No cerradão, Fs repetiu o padrão bimodal observado em $R$. guianensis, com um pico máximo entre 9 e $10 \mathrm{~h}$ e um outro às $17 \mathrm{~h}$. No campo sujo, Gs atingiu seu valor máximo as $9 \mathrm{~h}$. Em seguida Gs diminuiu lentamente durante o resto do período luminoso, com um pequeno aumento por volta das 14 horas. No cerradão, ocorreu um pico na condutância estomática por volta das $8 \mathrm{~h}$ e um outro pico menor entre 15 e $16 \mathrm{~h}$.

\section{Fluxos totais e transpiração foliar total}

Indivíduos da mesma espécie não diferiram $(\mathrm{P}>0,05)$ quanto aos valores integrados de fluxo e transpiração foliar, entre o campo sujo e cerradão (Tabela 2).

Diferenças entre as espécies ocorreram somente no cerradão, em que Roupala montana apresentou valores integrados de fluxo maiores ( $\mathrm{P}=$ $0,020)$ que Rapanea guianensis. Por outro lado, não ocorreram diferenças significativas para os valores integrados de transpiração foliar. As duas espécies não diferiram entre si nos valores integrados de fluxo e transpiração foliar no campo sujo.

TABELA 2 - Fluxo total e transpiração foliar total de Rapanea guianensis e Roupala montana no campo sujo e no cerradão.

\begin{tabular}{|c|c|c|c|c|c|}
\hline Data & $\begin{array}{l}\text { Fluxo total } \\
\left(\mathbf{l d}^{-1}\right)\end{array}$ & $\begin{array}{c}\text { Transpiração } \\
\text { foliar total } \\
\left(\operatorname{lm}^{-2} \mathbf{d}^{-1}\right)\end{array}$ & Data & $\begin{array}{l}\text { Fluxo total } \\
\quad\left(\mathbf{l d}^{-1}\right)\end{array}$ & $\begin{array}{c}\text { Transpiração } \\
\text { Foliar total } \\
\left(\operatorname{lm}^{-2} d^{-1}\right)\end{array}$ \\
\hline \multicolumn{3}{|c|}{ Campo sujo } & \multicolumn{3}{|c|}{ Cerradão } \\
\hline \multicolumn{6}{|c|}{ Rapanea guianensis } \\
\hline $16 / 8 / 97$ & 1,56 & 2,30 & $17 / 8 / 97$ & 1,50 & 0,89 \\
\hline $23 / 8 / 97$ & 1,88 & 2,69 & $24 / 8 / 97$ & 1,23 & 1,27 \\
\hline $26 / 8 / 97$ & 1,25 & 0,84 & $27 / 8 / 97$ & 0,82 & 1,00 \\
\hline Média & 1,56 & 1,94 & Média & 1,18 & 1,05 \\
\hline \multicolumn{6}{|c|}{ Roupala montana } \\
\hline $16 / 8 / 97$ & 4,55 & 1,32 & $17 / 8 / 97$ & 2,08 & 0,51 \\
\hline 20/8/97 & 1,84 & 0,63 & $21 / 8 / 97$ & 2,37 & 1,33 \\
\hline $26 / 8 / 97$ & 2,36 & 0,42 & 27/8/97 & 1,87 & 1,34 \\
\hline Média & 2,91 & 0,79 & Média & 2,10 & 1,03 \\
\hline
\end{tabular}




\section{Potencial hídrico foliar}

As curvas diárias de potencial hídrico foliar para as duas espécies são apresentadas na Figura 3. Os valores encontrados pela manhã estavam próximos a $-0,7 \mathrm{MPa}$, diminuindo ao longo do dia, e atingindo os valores mínimos entre 13 e 15 horas. Apesar de os valores de $\psi$ aumentarem lentamente ao longo da tarde, não alcançaram os valores máximos observados no início da manhã.

Pela Tabela 3 verifica-se os valores de potencial hídrico máximos $\left(\psi^{\text {máx }}\right)$ medidos ao amanhecer, e mínimos $\left(\psi^{\mathrm{min}}\right)$ medidos ao meio-dia, durante o período de 16 a 27 de agosto de 1997, para as folhas das duas espécies. Para ambas as espécies, não houve diferenças nos valores de $\psi^{\text {máx }}$ entre o campo sujo e o cerradão. Por outro lado, os valores de $\psi^{\text {min }}$ de $R$. guianensis foram maiores ( $\mathrm{P}=0,044)$ no cerradão do que no campo sujo, enquanto os valores $\psi^{\min }$ de $R$. montana não diferiram entre as duas fitofisionomias.

Comparando-se as duas espécies, $R$. montana apresentou valores de $\psi^{\text {min }}$ mais negativos ( $\mathrm{P}=0,024$ ) do que $R$. guianensis nas duas fitofisionomias.

\section{Relação entre fluxo de seiva e déficit de pressão de vapor}

Na Figura 4 e 5 estão representados o efeito do DPV sobre o fluxo de seiva para Rapanea guianensis e Roupala montana, no campo sujo e cerradão.

No início do período luminoso, nota-se uma relação positiva entre um aumento de DPV e de Fs, até Fs atingir um valor máximo. Vamos chamar de valor limite o valor de DPV correspondente a esse fluxo de seiva máximo.

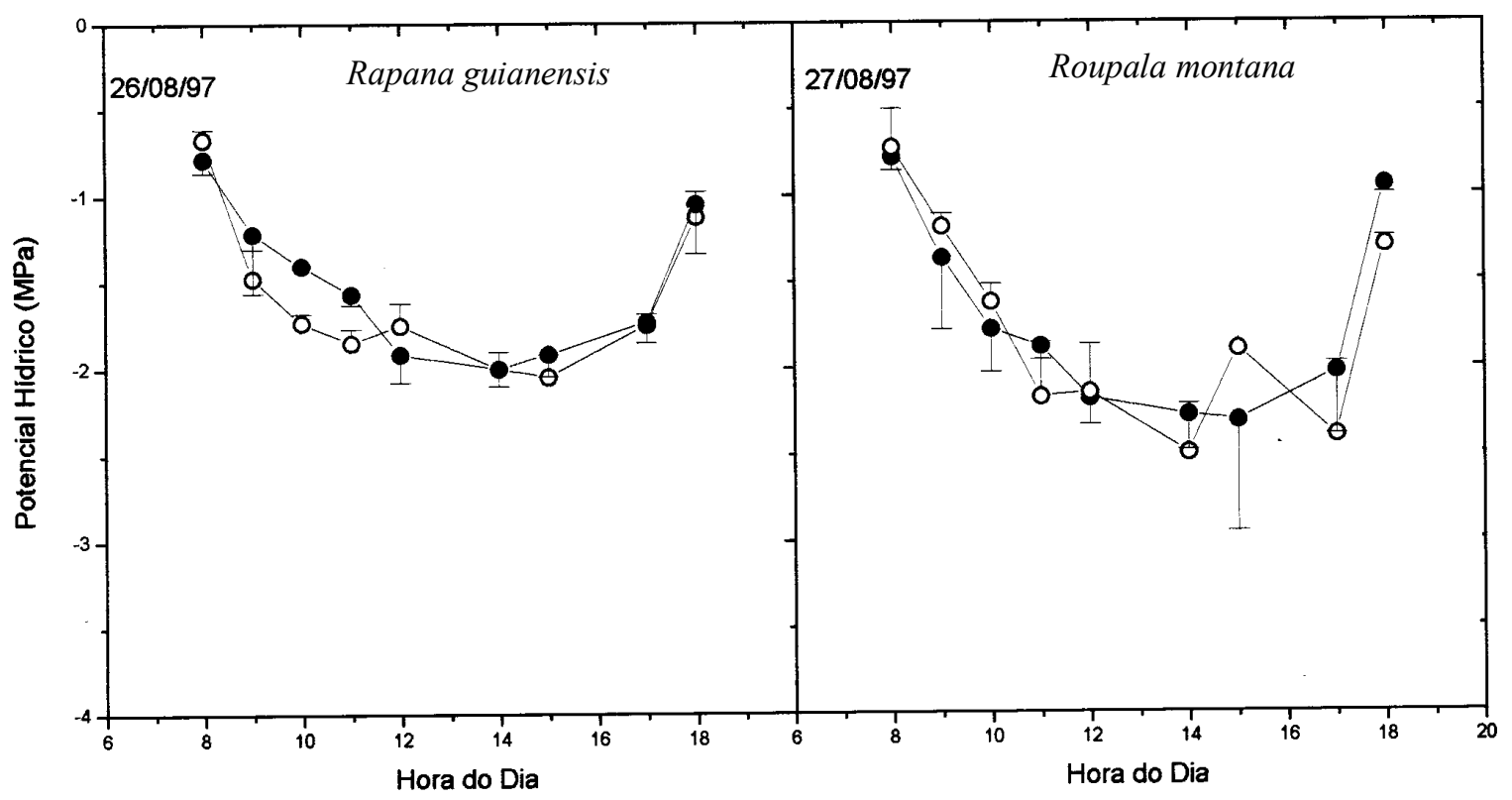

FIGURA 3 - Curso diário do potencial hídrico foliar das espécies Rapanea guianensis e Roupala montana, no campo sujo (o) e cerradão (•) nos dias 26 e 27 de agosto de 1997. 
TABELA 3 - Médias dos valores máximos (medidos ao amanhecer) e mínimos (medidos ao meio dia) do potencial hídrico foliar $\left(\psi^{\text {máx }}, \psi^{\text {min }}, \mathrm{MPa}\right.$ ) de Rapanea guianensis e Roupala montana no campo sujo e no cerradão.

\begin{tabular}{|c|c|c|c|c|c|}
\hline Data & $\psi^{\min }$ & $\psi^{\text {máx }}$ & Data & $\psi^{\min }$ & $\psi^{\text {máx }}$ \\
\hline \multicolumn{3}{|c|}{ Campo sujo } & \multicolumn{3}{|c|}{ Cerradão } \\
\hline \multicolumn{6}{|c|}{ Rapanea guianensis } \\
\hline $16 / 8 / 97$ & $-1,63$ & $-0,30$ & $17 / 8 / 97$ & $-2,03$ & $-0,36$ \\
\hline $23 / 8 / 97$ & $-1,09$ & $-0,46$ & $24 / 8,97$ & $-2,30$ & $-0,65$ \\
\hline $26 / 8 / 97$ & $-2,05$ & $-0,66$ & $27 / 8 / 97$ & $-2,00$ & $-0,78$ \\
\hline Média & $-1,59$ & $-0,47$ & Média & $-2,11$ & $-0,59$ \\
\hline \multicolumn{6}{|c|}{ Roupala montana } \\
\hline $16 / 8 / 97$ & $-2,36$ & $-0,28$ & $17 / 8 / 97$ & $-2,57$ & $-0,35$ \\
\hline $20 / 8 / 97$ & $-2,35$ & $-0,40$ & $21 / 8 / 97$ & $-2,40$ & $-0,38$ \\
\hline $26 / 8 / 97$ & $-2,31$ & $-0,78$ & $27 / 8 / 97$ & $-2,50$ & $-0,70$ \\
\hline Média & $-2,34$ & $-0,48$ & Média & $-2,49$ & $-0,47$ \\
\hline
\end{tabular}

Baseando-se nesse valor de DPV, o fluxo diminuiu, apesar de a demanda evaporativa continuar aumentando, o que mostra o controle estomático da transpiração. Essa redução de Fs devido ao controle estomático, ocorreu antes do meio-dia e manteve-se ao longo do período da tarde, pois para um mesmo valor de DPV, o fluxo é menor após o meio-dia. Esse padrão foi observado nas duas espécies, tanto no campo sujo como no cerradão. Para $R$. guianensis, o valor limite do DPV variou entre 2,0 e 3,5 $\mathrm{kPa}$ ( Figura 4 ) e para R. montana, entre 1,5 e $2,0 \mathrm{kPa}$ ( Figura 5). Para ambas as espécies, o valor limite do DPV foi semelhante no campo sujo e no cerradão.

\section{DISCUSSÃO}

A abertura estomática é dependente do estado hídrico da folha e da demanda evaporativa da atmosfera. Existem numerosas observações de que a condutância estomática diminui em reposta a um aumento do déficit de pressão de vapor entre a folha e o ar, e que a resposta está relacionada à taxa de transpiração foliar (Schulze, 1993, Yong et al., 1997). Em ambas as espécies, os estômatos exerceram um forte controle no fluxo transpiratório ao longo do dia. Roupala montana foi mais sensível ao DPV do que $R$. guianensis. A queda acentuada do fluxo de seiva, considerando-se os valores de DPV na faixa de 1,5 a $3,5 \mathrm{kPa}$, refletiu o controle estomático exercido por essas espécies em relação à alta demanda evaporativa da atmosfera. Esses resultados estão de acordo com o modelo proposto por Sarmiento et al., (1985), que concluíram que a transpiração das espécies lenhosas depende mais das condições atmosféricas do que da disponibilidade de água no solo. Além 


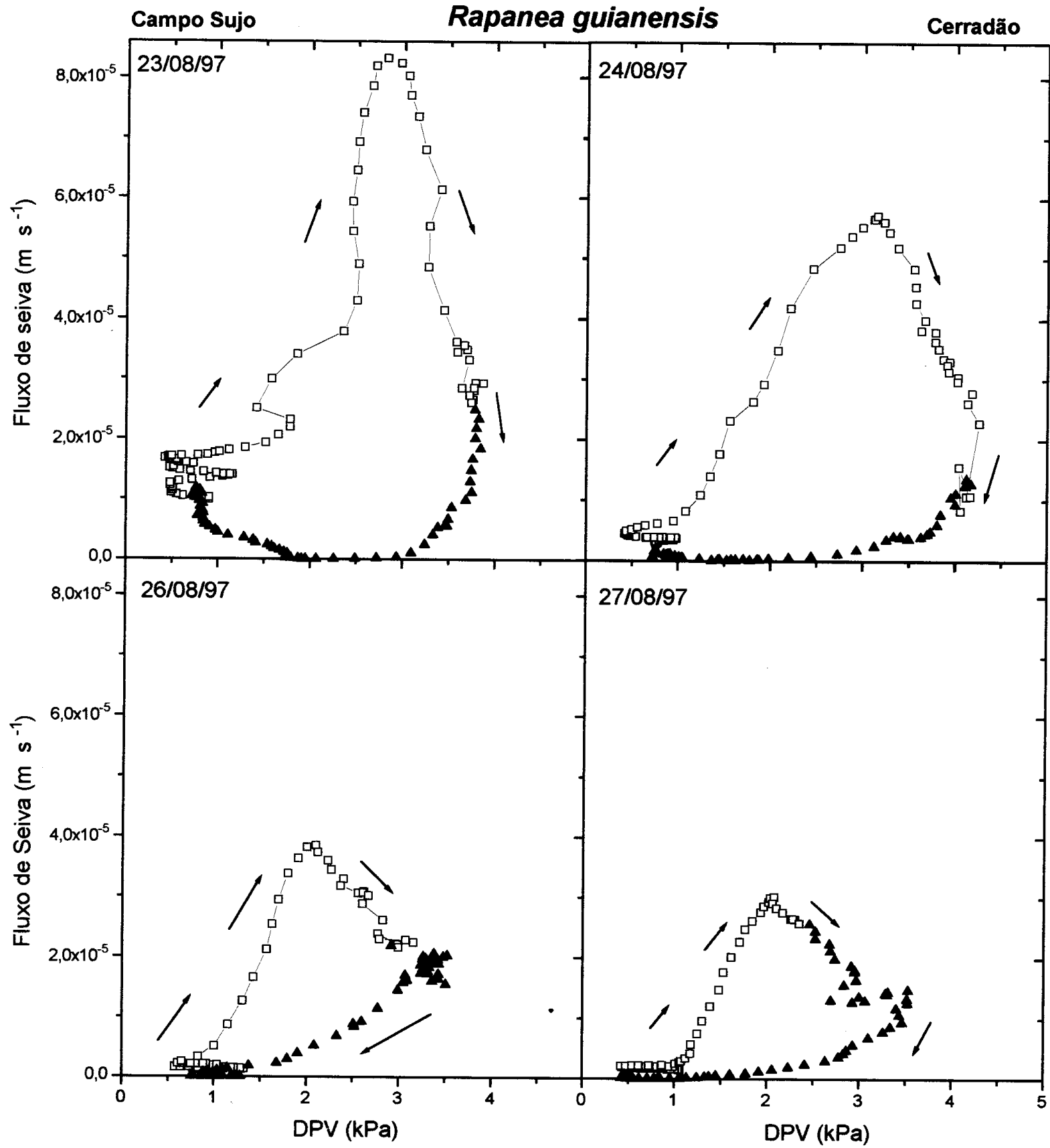

FIGURA 4 - Relação entre o fluxo de seiva e o déficit de pressão de vapor para Rapanea guianensis nos dias 23, 24, 26 e 27 de agosto de 1997. Os símbolos abertos correspondem aos valores obtidos antes das 12:00 h, enquanto que os símbolos fechados a valores obtidos após às 12:00 h. A direção das setas correspondem ao curso de aumento e decréscimo do DPV ao longo do dia.

R. Bras. Fisiol. Veg., 12(2):119-134, 2000. 


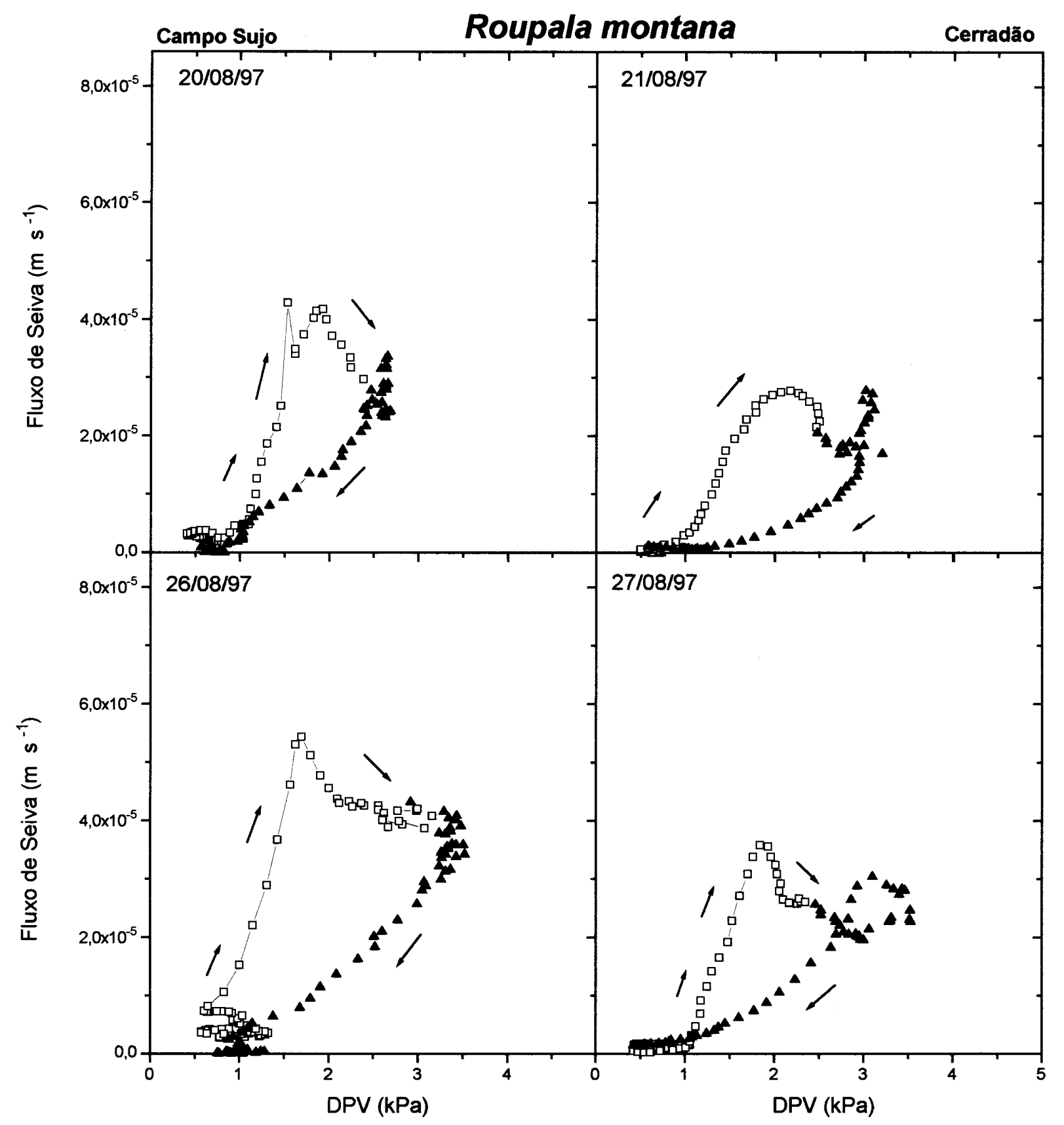

FIGURA 5 - Relação entre o fluxo de seiva e o déficit de pressão de vapor para Roupala montana nos dias 20, 21, 26 e 27 de agosto de 1997. Os símbolos abertos correspondem aos valores obtidos antes das 12:00 h, enquanto que os símbolos fechados a valores obtidos após às 12:00 h. A direção das setas correspondem ao curso de aumento e decréscimo do DPV ao longo do dia. 
disso, há um efeito sazonal na abertura estomática de plantas do cerrado. Na maioria dos casos, a condutância estomática diminui na estação seca, quando a demanda evaporativa da atmosfera aumenta consideravelmente (Perez e Moraes 1991, Moraes e Prado 1998; Franco 1998; Mattos, 1998). Meinzer et al., (1999), ao estudarem a regulação da transpiração em quatro espécies arbóreas sempre-verdes, em um cerrado sensu strictu do Distrito Federal, também observaram um rígido controle da transpiração via um controle estomático pronunciado, levando a limitações no fluxo de seiva, tanto na estação seca como na estação chuvosa.

Apesar da alta demanda evaporativa da atmosfera, os valores máximos de fluxo medido nas duas espécies, entre 0,13 a $0,541 . h^{-1}$, são baixos, quando comparados a outras espécies tropicais. Na Austrália, indivíduos de Eucalyptus regnas de $28 \mathrm{~m}$ de altura apresentaram fluxos diários de $251 . \mathrm{d}^{-1}$ (Vertessy et al., 1995). Em árvores de um bosque tropical da Guiana Francesa, mediram-se valores máximos de fluxo de $301 . \mathrm{h}^{-1}$ (Granier et al., 1996). Além do controle estomático nos momentos de maior demanda evaporativa, os baixos valores de fluxo em $R$. montana e $R$. guianensis são, em parte, função da reduzida superfície foliar transpirante da copa, na faixa de 0,7 a $4 \mathrm{~m}^{2}$ por indivíduo. Entretanto, esses valores estão na faixa encontrada em uma área de cerrado sensu strictu, em que quatro espécies lenhosas com porte entre 2 e $6 \mathrm{~m}$ apresentaram valores máximos de fluxo de seiva entre 0,7 e 1,45 1.h ${ }^{-1}$ (Meinzer et al., 1999).

A queda acentuada dos valores de potencial hídrico foliar, ao longo do dia, indica que a taxa de entrada de água não compensou a taxa de perda de água pela transpiração nas horas de maior demanda evaporativa. Os valores mínimos de potencial hídrico foliar de $R$. guianensis foram mais negativos $(\mathrm{P}<0,05)$ para as plantas do cerradão, enquanto para $R$. montana não apresentaram diferenças entre as duas fisionomias. Entretanto, a recuperação dos potenciais hídricos no fim do dia e os valores relativamente altos de $\psi$ ao amanhecer indicam que $R$. montana $e R$. guianensis teriam suficiente acesso às reservas de água do subsolo na estação seca, nos dois ambientes. Valores de $\Psi$ medidos ao amanhecer não diferiram para as duas espécies nas duas fisionomias estudadas. Padrões semelhantes de $\psi$ e valores na mesma faixa foram encontrados em outras árvores e arbustos em uma área de cerrado sensu strictu (Franco, 1998; Mattos, 1998; Meinzer et al., 1999) e no cerradão (Perez e Moraes 1991).

Pode-se concluir que ambas as espécies não foram capazes de extrair água do solo em quantidade suficiente para fazer frente à alta demanda evaporativa da atmosfera e exerceram um controle estomático rígido nas taxas de transpiração. Estes resultados e os obtidos por Meinzer (1999) sugerem que o modelo proposto por Sarmiento (1985), de que árvores e arbustos nas savanas neotropicais não restringem a taxa de transpiração na estação seca, não é válido para os cerrados do Brasil Central, tanto em nível foliar como no quse se refere ao indivíduo, não corroborando as afirmações de alguns autores (Ferri, 1944; Grisi, 1971) de que árvores do cerrado não exercem controle estomático e transpiram livremente. Apesar de não existirem diferenças no comportamento transpiratório dessas duas espécies em função de um aumento na densidade de indivíduos arbóreos, $R$. guianensis sofreu um maior déficit hidrico no cerradão nos momentos de maior demanda evaporativa da atmosfera, indicando uma menor disponibilidade hídrica nesse ambiente para esta espécie.

\section{AGRADECIMENTOS}

O presente trabalho foi financiado pelo CNPq, National Science Foundation e PRONEX. Somos gratos à Reserva Ecológica do IBGE, Brasília, pelo apoio logístico. Da mesma forma, agradecemos a Gabriela B. Nardoto e a Geogina Cardinoto, pela ajuda na coleta dos dados.

\section{REFERÊNCIAS}

CALDAS, L. S.; BRAVO, C.; PICCOLO, H. and FARIA, C. R. S. M. Measurement of leaf area with a hand-scanner linked to a microcomputer. Revista 
Brasileira de Fisiologia Vegetal. 4(1): 17-20, 1992.

COUTINHO, L. M. O conceito de cerrado. Revista Brasileira de Botânica 1:17-23, 1978.

FERRI, M. G. Transpiração de plantas permanentes dos cerrados. Bol Fac. Filos. Ciências Letras Univ. S. Paulo, Botânica, 4:161-224, 1944.

FRANCO, A.C. Seasonal patterns of gas exchange, water relations and growth of Roupala montana, an evergreen savanna species. Plant Ecology. 136: 6976, 1998.

GOLDSTEIN, G.; SARMIENTO, G. and MEINZER, F. Patrones diários y estacionales em las relaciones hídricos de árboles simpreverdes de la savana tropical. Acta Oecologica. 7(2): 107 - 109, 1986.

GRANIER, A , HUC, R. and BARIGAH, S. T. Transpiration of natural rain forest and its dependence on climatic factors. Agricultural and Forest Meteorology 78: 19-29, 1996.

GRANIER, A. Evaluation of transpiration in a Douglasfir stand by means of sap flow measurments. Tree Physiology 3: 309-320, 1987.

GRANIER, A. Une nouvelle méthode pour la mesure du flux de sève brute dans le tronc des arbres. Ann. Sci. For. 42 (2): 193-200, 1985.

GRISI, B. M. Contribuição ao conhecimento de ecologia vegetal do cerrado. Balanço hidríco de dois espécimes de Ouratea spectabilis (Mart) Engl. In: Ferri, M. G. (Ed.) III Simpósio sobre o cerrado. São Paulo, Editora Edgard Blucher, EDUSP, p. 86-89., 1971.

JACKSON, P. C., F. C. MEINZER, M. BUSTAMANTE, G. GOLDSTEIN, A. FRANCO, P. W. RUNDEL, L. CALDAS, E. IGLER and F. CAUSIN. Partitioning of soil water among tree species in a Brazilian Cerrado ecosystem. Tree Physiology 19: 717-724, 1999.

JONES, H. G. Plants and microclimate: A quantitative approach to environmental plant physiology. Second Edition. Cambridge Unyversity Press, 1992. $85 \mathrm{p}$.
MATTOS, E. A. Perspectives in comparative ecophysiology of some brazilian vegetation types: leaf $\mathrm{CO}_{2}$ and $\mathrm{H}_{2} \mathrm{O}$ gas exchange, chlorophyll $a$ fluorescence and carbon isotope discrimination. In Scarano, F. R. and Franco. A. C. (eds.). Ecophysiological strategies of xerophytic and amphibious plants in the neotropics. Series Oecologia Brasiliensis, PPGE-UFRJ. Rio de Janeiro, Brazil, 4:01-22, 1998.

MEINZER, F. C.; GOLDSTEIN.; FRANCO, A. C.; BUSTAMANTE, M.; IGLER, E.; JACKSON, P. , CALDAS, L. and RUNDEL, P. W. Atmospheric and hydraulic limitations on transpiration in Brazilian cerrado woody species. Functional Ecology. 13: 273-282, 1999.

MORAES, J.A.P.V. and PRADO, C. H. B. A. Photosynthesis and water relations in Cerrado vegetation. In Scarano, F. R. and A. C. Franco (eds.). Ecophysiological atrategies of Xerophytic and amphinbious plants in the neotropics. Series Oecologia Brasiliensis, PPGE-UFRJ. Rio de Janeiro, Brazil. 1998. vol. 4, p. 45-63.

NARDOTO, G. B.; SOUZA, M. P. e FRANCO, A. C. Estabelecimento e padrões sazonais de produtividade de Kielmeyera coriaceae (Spr) Mart. nos cerrados do planalto Central: efeitos do estresse hídrico e sombreamento. Revista brasileira de Botânica, 21:313-319, 1998.

PEREZ, S.C.J.G.A. e MORAES, J.A.P.V. Determinação de potencial hídrico, condutância estomática e potencial osmótico em espécies dos estratos arbóreo, arbustivo e herbáceo de um cerradão. Revista Brasileira de Fisiologia Vegetal, 391: 27 - 37, 1991.

RAWITSHER, F. The water economy of the campos cerrados in southern Brazil. Journal of Ecology, 36(2): 237-268, 1948.

RAWITSHER, F., FERRI, M.G. e RACHID, M. Profundidade dos solos e vegetação em campos cerrados do Brasil Meridional. Anais da Academia Brasileira de Ciências, T 15(4):267-296, 1943.

SARMIENTO, G.; GOLDSTEIN, G. and MEINZER, F. Adaptative strategies of woody species in neotropical savanas. Biological Review, 60: 315$355,1985$. 
SCHULZE, E. D. Soil, water deficits and atmospheric humidity as environmental signals. In Water deficits: plant responses from cell to community. Smith, J. A.C. and Griffiths, H. BIOS Scientific Publisher, Oxford, United Kingdom, 98-125, 1993.

SMITH, D. M and ALLEN, S. J. Measurement of sap flow in plant stems. Journal of Experimental Botany, 47:(305): 1833-1844, 1996.

SOKAL, R.R and ROHLF, F. J. Biometry: the principles and practice of statistic in biological research. Ed. W. H. Freeman and Company, San Francisco, 395p., 1969.
VERTESSY, R. A.; BENYON, R. G.; O'SULLIVAN, S.K. and GRIBBEN, P.R. Relationship between stem diameter, sapwood area, leaf area and transpiration in a young mountain ash forest. Tree Physiology, 15: 559-567, 1995.

WARMING, E. Lagoa Santa. Et. Bidrag Tilden biologiske Plantegeografi. K. danske videns K. Skr 6. Copenhague. 362 p, 1892.

YONG, J. W. H.; WONG, S. C. and FARQUHAR, G. D. Stomatal responses to changes in vapour pressure difference between the leaf and air. Plant, Cell and Environment, 20: 1213-1216. 